\title{
Disease burden evaluation of fall-related events in the elderly due to hypoglycemia and other diabetic complications: a clinical review
}

This article was published in the following Dove Press journal:

Clinical Epidemiology

14 August 2014

Number of times this article has been viewed

\section{Usman H Malabu' \\ Venkat $N$ Vangaveti \\ Richard Lee Kennedy ${ }^{2}$ \\ 'School of Medicine and Dentistry, James Cook University, QLD, \\ Australia; ${ }^{2}$ Department of Medicine, Deakin University, VIC, Australia}

Video abstract

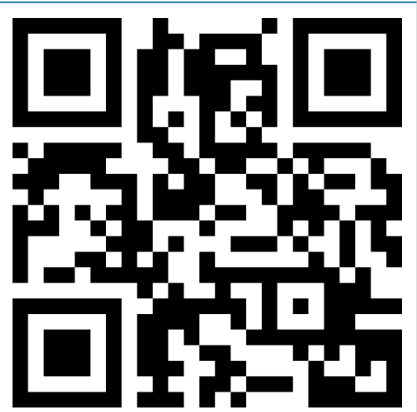

Point your SmartPhone at the code above. If you have a QR code reader the video abstract will appear. Or use: http://dvpr.es/lpfixdo
Correspondence: Usman H Malabu School of Medicine and Dentistry, James Cook University, I James Cook Drive, Douglas, QLD 48I4, Australia

Tel +6 I 744 33 I I I I

Fax +6I 744332239

Email usman.malabu@jcu.edu.au
Abstract: A hypoglycemia-induced fall is common in older persons with diabetes. The etiology of falls in this population is usually multifactorial, and includes microvascular and macrovascular complications and age-related comorbidities, with hypoglycemia being one of the major precipitating causes. In this review, we systematically searched the literature that was available up to March 31, 2014 from MEDLINE/PubMed, Embase, and Google Scholar using the following terms: hypoglycemia; insulin; diabetic complications; and falls in elderly. Hypoglycemia, defined as blood glucose $<4.0 \mathrm{mmol} / \mathrm{L}$ ( $70 \mathrm{mg} / \mathrm{dL}$ ) requiring external assistance, occurs in one-third of elderly diabetics on glucose-lowering therapies. It represents a major barrier to the treatment of diabetes, particularly in the elderly population. Patients who experience hypoglycemia are at a high risk for adverse outcomes, including falls leading to bone fracture, seizures, cognitive dysfunction, and prolonged hospital stays. An increase in mortality has been observed in patients who experience any one of these events. Paradoxically, rational insulin therapy, dosed according to a patient's clinical status and the results of home blood glucose monitoring, so as to achieve and maintain recommended glycemic goals, can be an effective method for the prevention of hypoglycemia and falls in the elderly. Contingencies, such as clinician-directed hypoglycemia treatment protocols that guide the immediate treatment of hypoglycemia, help to limit both the duration and severity of the event. Older diabetic patients with or without underlying renal insufficiency or other severe illnesses represent groups that are at high risk for hypoglycemia-induced falls and, therefore, require lower insulin dosages. In this review, the risk factors of falls associated with hypoglycemia in elderly diabetics were highlighted and management plans were suggested. A target hemoglobin A1c level between $7 \%$ and $8 \%$ seems to be more appropriate for this population. In addition, the first-choice drugs should have good safety profiles and have the lowest probability of causing hypoglycemia - such as metformin (in the absence of significant renal impairment) and incretin enhancers - while other therapies that may cause more frequent hypoglycemia should be avoided.

Keywords: hypoglycemia, diabetes complications, falls, fractures, elderly

\section{Introduction}

Diabetes is one of the most common chronic conditions in older adults. ${ }^{1}$ The number of elderly individuals with diabetes is also growing worldwide because of increased life expectancy and the incidence of the disease in the general population. ${ }^{1,2}$ In 2013 , it was estimated that 382 million people globally had diabetes, and this number is predicted to increase to 592 million by $2035 .{ }^{3}$ The burden of diabetes in the elderly is felt most in industrially advanced countries. ${ }^{4}$ For instance, of the 3.2 million people in the UK with diabetes, at least half are over 65 years old. ${ }^{4}$ The prevalence of diabetes in the elderly is more than $10 \%$ when compared with $6 \%$ in the general adult population, 
and it approaches $25 \%$ in nursing home residents. ${ }^{4,5}$ The management of elderly patients presents unique challenges. Episodes of hypoglycemia are a major complication of the treatment of diabetes with insulin and some other oral medications. ${ }^{6,7}$ The consequences of hypoglycemia may be much greater in the frail older population than in younger adults. ${ }^{6}$ For instance, falls may be the first presentation of a hypoglycemic symptom in the elderly, with devastating consequences including bone fracture, deteriorating quality of life, and death. ${ }^{6,7}$ Apart from the high rate of falls in this group, the prevalence of osteoporosis is also high, largely due to coexisting diseases including diabetes, which are associated with poor bone health. ${ }^{8}$ Furthermore, multiple medications have been implicated in causing osteoporosis in the older diabetic population. ${ }^{8}$ The aim of this review was to highlight the risk factors of hypoglycemia-induced falls in the diabetic elderly population and to recommend preventive measures aimed at minimizing the event. MEDLINE/ PubMed (US National Library of Medicine, Bethesda, MD, USA), Embase (Elsevier BV, Amsterdam, the Netherlands), and Google Scholar (Google, Mountain View, CA, USA) were searched on March 31, 2014 using combinations of the following search terms: hypoglycemia; insulin; diabetic complications and falls in elderly.

\section{Prevalence and symptoms of hypoglycemia in the elderly}

The true prevalence of hypoglycemia in the elderly is unknown, largely due to variations in its definition. ${ }^{7}$ Most studies defined hypoglycemia by relying on the recall of hypoglycemic events by participants. ${ }^{9,10}$ The accurate recall of hypoglycemia is notably difficult in any age group, and more so in the elderly population. ${ }^{11}$ For epidemiological purposes, severe hypoglycemia is usually defined as low blood glucose levels requiring external assistance for treatment. ${ }^{7}$ This is easier to measure, as it is usually more dramatic and offers good precision in terms of recall for up to 1 year in both types of diabetes. ${ }^{910}$ The frequency of severe hypoglycemia can also be corroborated with documentary evidence from medical emergency services. ${ }^{11}$ Thus, knowledge of the symptoms of hypoglycemia in the elderly is often poor. ${ }^{11,12}$ On the other hand, mild episodes of hypoglycemia are under-recognized by patients, relatives or carers, and their health care providers. ${ }^{12}$ Studies have shown a poor correlation between the recall of hypoglycemia by relatives and patients, ${ }^{13}$ with relatives tending to recall more episodes than patients. Furthermore, the recognition of mild hypoglycemia is made more difficult as the hypoglycemia symptom profile changes with age, as do the glycemic thresholds for symptom generation and cognitive impairment. ${ }^{14}$ Even if hypoglycemia is recognized, patients are known to under-report this to their doctors. ${ }^{15}$ The annual prevalence of insulin-induced hypoglycemia in type 2 diabetic patients was reported to be high, accounting for up to $25 \%$ of cases, as compared to $7 \%$ of cases that were caused by sulphonylurea. ${ }^{6}$ In support of this, fewer cases of hypoglycemia caused by oral antidiabetic agents were observed. For instance, in a retrospective assessment in the elderly population, Bramlage et a ${ }^{16}$ noted that only $1 \%$ of reported episodes of symptomatic hypoglycemia was induced by oral antidiabetic agents.

The symptoms of hypoglycemia derive from a physiological response to the change in glucose. ${ }^{17}$ Although symptoms may differ between people, in younger adults, these are usually easy to perceive. ${ }^{18}$ Hypoglycemia scores were developed from analyzing the most common symptoms that were reported by people experiencing hypoglycemia, ${ }^{18,19}$ and they comprise autonomic symptoms such as sweating, pounding heart, and neuroglycopenic symptoms in the form of confusion and lightheadedness, and nonspecific symptoms such as malaise. In older people, the symptoms of hypoglycemia may be missed due to the coexistence of other nonspecific agedrelated ailments, ${ }^{20,21}$ and there is an overall reduced subjective awareness of hypoglycemia with increasing age. ${ }^{22}$ In younger people, autonomic symptoms of hypoglycemia tend to be more prominent than neuroglycopenic symptoms, although the latter also occur. ${ }^{22}$ These autonomic symptoms of hypoglycemia become less prominent with the increasing duration of diabetes, and also in older patients with diabetes. ${ }^{21,23}$ It has been postulated that this change in symptoms may be related to a reduced end-organ response in older people. ${ }^{21}$

\section{Hypoglycemia-induced falls in the elderly}

Falls among the elderly is one of the most frequent causes of unintentional injuries, causing close to $90 \%$ of hip and wrist fracture ${ }^{24,25}$ and $60 \%$ of head injuries. ${ }^{26}$ The complications arising from long-term diabetes - namely, diabetic neuropathy, retinopathy, and foot ulcer - are known to cause falls in elderly patients. ${ }^{27} \mathrm{~A}$ range of risk factors has been shown to cause falls in diabetic patients. These include age, a lack of balance, insulin therapy, a history of heart disease, osteoarthritis, peripheral neuropathy, a higher body mass index, and poor lower extremity performance. ${ }^{28-30}$ In general, elderly diabetic patients have been found to be at an increased risk of falls and disability. ${ }^{31,32}$ Hypoglycemia, one of the most feared acute complications of diabetes treatment, has been 
shown to increase the risk of falls. ${ }^{32}$ The symptoms that lead to falls in hypoglycemic patients include trembling, shakiness, a decrease in cognitive ability, and palpitations. ${ }^{33,34}$

A fall during hypoglycemia can cause soft tissue damage, bone fractures, and head injuries, which may further cause delirium leading to recurrent falls. ${ }^{35}$ Frail elderly people, many of whom have other comorbidities such as osteoporosis, may be particularly vulnerable to bone fractures following a fall. ${ }^{24}$ The pain and disability that such trauma imposes on the affected individual and his or her relatives or carers, and the enormous economic burden placed on health care resources, have recently been investigated, showing substantial insurance claims in the elderly population. ${ }^{33}$ The risk of accidents resulting in hospital visits among people with type 2 diabetes on medications (excluding insulin) was assessed retrospectively in a large United States health insurance database. ${ }^{33}$ Hypoglycemia was associated with significantly increased hazards for any accident (hazard ratio [HR]: 1.39; 95\% confidence interval $[\mathrm{CI}]: 1.21-1.59 ; P<0.001)$, accidental falls (HR: 1.36; 95\% CI: 1.13-1.65; $P<0.001$ ), and motor vehicle accidents (HR: 1.82; 95\% CI: 1.18-2.80; $P<0.01) .{ }^{36}$ Similarly, a large retrospective observational study of more than 360,000 patients with type 2 diabetes aged over 65 years found $4.7 \%$ of those who had a documented hypoglycemic episode over the course of 1 year had a $70 \%$ higher chance of having a fall-related fracture (odds ratio: 1.7 ; 95\% CI: $1.58-1.83$ ); the odds still remained high even after correcting for potential confounders, such as the presence of diabetic peripheral neuropathy. ${ }^{33}$ In support of this, retrospective and case control studies have also suggested increased hypoglycemia-related falls and fractures particularly in people with strict glycemic control who were on insulin therapy, but not among those on oral antidiabetes agents. ${ }^{10-12}$ Thus, in subjects with type 2 diabetes receiving insulin, hypoglycemia was associated with a significantly higher risk of accidents resulting in hospital visits, including accidents related to driving and falls. ${ }^{35}$

Hypoglycemia has a major adverse impact on quality of life among the elderly population. ${ }^{33,34}$ It is well known in clinical practice that patients fear hypoglycemia more than any other diabetic complications. ${ }^{37}$ In the aged, hypoglycemia has been linked to poor outcomes - not only to falls and fractures, but also to an increased risk of accidents, hospitalizations, in-hospital mortality, frailty, and the long-term impairment of cognition including a risk of dementia. ${ }^{32,34-38}$ It is also associated with electrophysiological changes in the form of a prolonged QT interval - a known precipitant of cardiac dysrhythmia, and which may lead to falls in the elderly. ${ }^{39}$

\section{Insulin and glycemic control leading to falls}

Kennedy et $\mathrm{al}^{40}$ identified that insulin-treated diabetic patients were more likely to experience falls during a hypoglycemic episode. The study also identified that patients treated with insulin were more likely to sustain a fracture during the fall. The rate of accidents in insulin-treated patients was significantly higher when compared to noninsulin-treated subjects. The profile of the insulin-treated patients was observed to be as follows: more women than men; an older age group; and with those with an increased length of hospitalization. The nature of the fracture was predominantly at the peripheral sites. Women were also more likely to develop fractures as a result of falls when compared with men. ${ }^{41}$ The number of recurrent falls was found to be much higher among diabetic patients. The factors that attributed to an increased risk of falls included the number of medications taken, increased levels of pain, a lack of physical activity, grip strength, and cognitive impairment. ${ }^{42}$ The role of glycemic control as a risk factor for falls has been controversial. Miller et $\mathrm{l}^{43}$ reported no relation between glycemic control and the risk of falls. Examining the risk factors for falls in diabetic patients, Tilling et $\mathrm{al}^{44}$ reported that poorly controlled diabetic subjects were more prone to falls. Falls in elderly diabetics with or without hypoglycemia are common, accounting for up to $31 \%$ of reported episodes per year. ${ }^{7,45}$ Interestingly, hemoglobin $\mathrm{A}_{1 \mathrm{c}}\left(\mathrm{HbA}_{1 \mathrm{c}}\right)$ levels did not affect the risk of falls in patients not using insulin. However, patients with $\mathrm{HbA}_{1 \mathrm{c}}<6 \%$ and those using insulin were found to be at a higher risk of falls. ${ }^{45}$ Regulating $\mathrm{HbA}_{1 \mathrm{c}}$ levels is of paramount importance in managing diabetes. While the regulation of $\mathrm{HbA}_{1 \mathrm{c}}$ is achieved by health practitioners, it may also help in delaying the long-term complications associated with diabetes, and thereby falls as well. ${ }^{45}$

\section{Diabetic microvascular complications leading to falls}

Peripheral neuropathy has been recognized as one of the risk factors for falls. DeMott et al ${ }^{46}$ reported a significant association between falls and peripheral neuropathy. Diabetic subjects with peripheral neuropathy have been shown to have postural instability leading to falls. ${ }^{47}$ Dukas et al ${ }^{48}$ identified low creatinine clearance as an independent risk factor for falls. In their study examining the risk factors contributing to falls in a diabetic cohort, Schwartz et a ${ }^{28}$ identified microvascular complications as one of the risk factors. The study found that reduced peripheral nerve function, vision impairment, and poor renal function attributed to falls in diabetic patients. ${ }^{28}$ 
When investigating urge incontinence in elderly women, Brown et $\mathrm{al}^{49}$ found that falls and fractures occurred independent of urge incontinence. The authors suggested that the early diagnosis and treatment of incontinence could help decrease falls in elderly people. Older individuals are often known to have difficulties in managing urinary frequency, as they rush to the bathroom to avoid urge incontinence, making them potentially vulnerable to falls. ${ }^{49}$

\section{Oral antidiabetic medications contributing to falls and fracture}

Medication is one of the risk factors associated with falls. ${ }^{42}$ It has been established that the use of multiple prescribed medications in general increases the risk of falls in elderly people. ${ }^{50}$ When studied specifically in a diabetic population, Huang et $\mathrm{al}^{51}$ found that diabetic patients taking more than four medications were at a higher risk of falls. With an increase in medications, the associated risk of falling increased as well. Diabetic subjects on insulin are at higher risk of hypoglycemia and falls than those on oral agents. ${ }^{7,35}$ Of those on oral antidiabetic medications, the risk of hypoglycemia is higher among subjects on sulphonylurea than those on other oral agents. ${ }^{16}$ On the other hand, the use of oral insulin sensitizers was not associated with falls. ${ }^{52}$ For example thiazolidinedione (TZD) and metformin have not been shown to increase the risk of falls. ${ }^{52,53}$ However, TZD was reported to increase the risk of fractures in diabetic patients by lowering bone formation and accelerated bone loss. ${ }^{54}$ No risk has been attributed to falls when patients used glucagon-like peptide-1 analogs or dipeptidyl peptidase- 4 inhibitors. ${ }^{55}$ A range of risk factors contributing to falls is shown in Table 1.

Table I Risk factors contributing to hypoglycemia-induced falls in elderly subjects with diabetes

\begin{tabular}{|c|c|c|}
\hline Aspect studied & $\begin{array}{l}\text { Risk compared with } \\
\text { controls }(95 \% \mathrm{Cl})\end{array}$ & $P$-value \\
\hline Diabetes $^{42}$ & HR: 1.63 (1.06-2.52) & 0.017 \\
\hline Poorly controlled DM ${ }^{44}$ & RR: 7.86 (2.94-20.79) & $<0.05$ \\
\hline Insulin ${ }^{40}$ & RR: 1.97 (I.68-2.32) & $<0.001$ \\
\hline Insulin 28 & OR: I.68 (I.37-2.07) & $<0.05$ \\
\hline Insulin and $\mathrm{HbA}_{\mathrm{Ic}}<6 \%{ }^{45}$ & OR: 4.36 (I.32-14.46) & $<0.05$ \\
\hline Renal impairment ${ }^{48}$ & OR: 3.68 (I.38-9.82) & 0.009 \\
\hline \multirow[t]{3}{*}{ Medications list ${ }^{51}$} & $\begin{array}{l}\text { I. } 4-5 \text { medications; } \\
\text { HR: I.22 (I.04-I.43) }\end{array}$ & - \\
\hline & $\begin{array}{l}\text { 2. 6-7 medications; } \\
\text { HR: I.33 (I.12-1.58) }\end{array}$ & $<0.01$ \\
\hline & $\begin{array}{l}\text { 3. }>7 \text { medications; } \\
\text { HR: I.79 (I.34-I.89) }\end{array}$ & $<0.01$ \\
\hline Foot ulcers ${ }^{41}$ & $\begin{array}{l}\text { Insensate feet; OR: I.87 } \\
(1.1-3.2)\end{array}$ & $<0.01$ \\
\hline
\end{tabular}

Abbreviations: $\mathrm{Cl}$, confidence interval; $\mathrm{HR}$, hazard ratio; $\mathrm{DM}$, diabetes mellitus; $\mathrm{RR}$, relative risk; OR, odds ratio; $\mathrm{HbA}_{\mathrm{Ic}}$, hemoglobin $\mathrm{A}_{\mathrm{Ic}}$.

\section{Mechanism of falls due to diabetes}

Falls in elderly diabetic subjects may be due to multiple factors. Apart from hypoglycemia, other well recognized complications of long-standing diabetes mellitus including peripheral neuropathy, impaired vision due to diabetic retinopathy or cataracts, autonomic neuropathy, and diabetic foot ulcers can each contribute meaningfully to fall risk through multiple mechanisms. ${ }^{27}$ The blurring of vision from hyperglycemia or hypoglycemia with an attendant osmotic effect on the lenses has also been linked to falls in diabetic elderly subjects. ${ }^{56,57}$ The global assessment of visual impairment has demonstrated a trend towards greater visual impairment in diabetics as compared with nondiabetics, albeit this is not significant and thus may signify the importance of determining other risk factors contributing to falls in subjects prone to hypoglycemia. ${ }^{56}$ Numerous studies suggested the possible link between falls and diabetes among the community-dwelling elderly population, ${ }^{31,38,58}$ with a significant risk being linked to proprioceptive deficits, impaired work performance, and strength of patients' leg muscles. ${ }^{38,59,60}$ Furthermore, orthostatic hypotension due to underlying autonomic neuropathy in elderly diabetic subjects has been linked to increased risk of falls. ${ }^{61,62}$ However, the contribution of orthostatic hypotension in causing falls in this group of the population has been questioned by others. ${ }^{63}$ Therefore, it is unlikely that the higher fall rate that was observed in diabetics was attributable to differences in orthostatic changes in blood pressure alone. The lack of an observed significant difference in the prevalence of orthostatic hypotension or visual impairment suggests that other factors, perhaps related to peripheral neuropathies or diabetic foot complications, play a greater causal role. ${ }^{31}$ Further studies confirming these findings in larger datasets while evaluating for the putative mechanism in relation to hypoglycemic episodes would be required.

\section{Diabetes and fracture risk}

Diabetes has been linked to an increased risk of osteoporosis. ${ }^{64}$ Although type 1 diabetes has been shown to be associated with lower bone mass, both types of diabetes have lower bone quality, even though patients with type 2 diabetes have higher bone mineral density values. ${ }^{65}$ Thus, those in the elderly diabetic population have a higher risk of fractures than do their non-diabetic counterparts. Furthermore, low serum testosterone levels have been reported to be common in the elderly diabetic male population, with a high prevalence of osteoporosis. ${ }^{66}$ Apart from diabetes predisposing an individual to poor bone health, antidiabetic agents such as metformin have been reported to cause B12 malabsorption, leading to neuropathy and a risk of falls in 
elderly diabetics ${ }^{67}$ To date, no randomized controlled trials have confirmed an association between metformin and vitamin B12 malabsorption. Recently, the TZD group of oral antidiabetic agents has been linked to osteoporotic fractures in women, though age stratification has not been studied. ${ }^{6}$ It has been suggested that TZD may cause bone loss and further increase fracture risk, placing it in the category of drugs that cause secondary osteoporosis. ${ }^{69}$ The mechanism of TZD-induced bone loss includes unbalanced bone remodeling processes resulting from decreased bone formation and increased bone resorption. ${ }^{69}$ Risk factors for the development of TZD-induced secondary osteoporosis are advanced age, female sex, and duration of treatment. ${ }^{68,69}$ Human and animal studies suggest that aging and estrogen deficiency confound TZD-induced bone loss and this combination (ie, aging and estrogen deficiency) may play a significant role in the pathogenesis of secondary osteoporosis. ${ }^{68,69}$

\section{Prevention of hypoglycemia-induced falls in elderly diabetic patients}

A holistic approach is necessary to prevent hypoglycemiainduced falls in the elderly diabetic subject. ${ }^{70,71}$ This is achieved by evaluating and addressing the risk factors that lead to falls, so as to ensure that preventive measures outweigh risk factors (Figure 1). Individualizing targets for diabetic control has been recommended particularly in the elderly, so as to minimize hypoglycemia while maintaining reasonable blood glucose control..$^{70}$ In the elderly, an

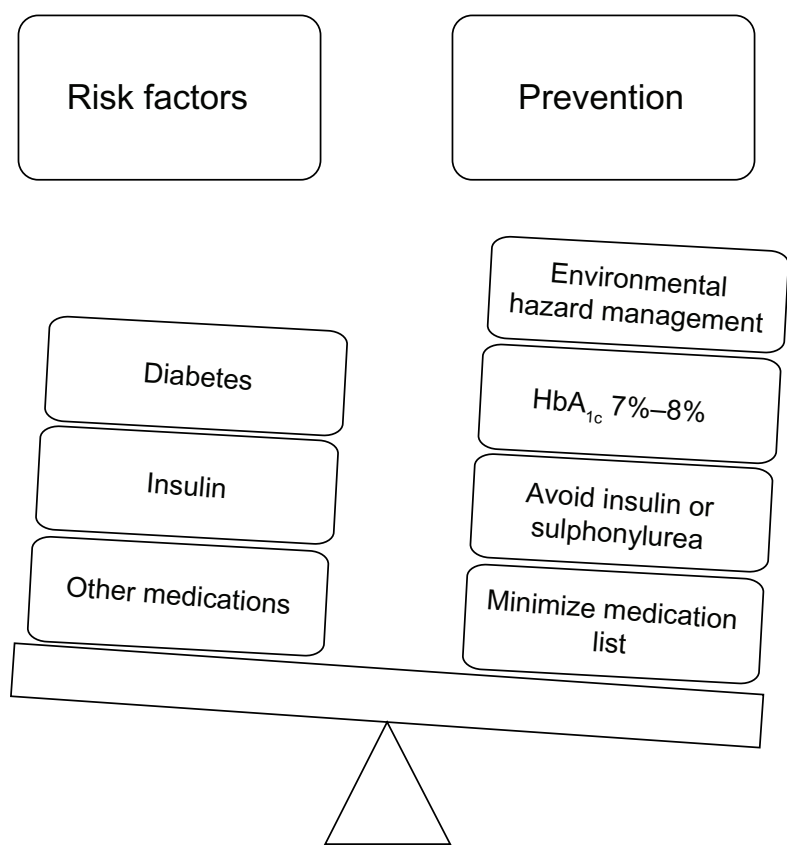

Figure I Key factors in preventing hypoglycemia-induced falls in the elderly. Abbreviation: $\mathrm{HbA}_{\mathrm{Ic}}$, hemoglobin $\mathrm{A}_{\mathrm{Ic}}$.
$\mathrm{HbA}_{1 \mathrm{c}}$ target of $<7.5 \%$ or even $8 \%$ has been advised by the American Diabetes Association and the European Association for the Study of Diabetes. ${ }^{71}$ Antidiabetic medications noted more likely to cause hypoglycemia, such as insulin/ sulphonylurea have been suggested to be used as second line agents in elderly diabetic subjects. ${ }^{70}$ To this end, the use of incretin-based therapy and metformin, which have a minimal risk of hypoglycemia, is plausible. ${ }^{71}$ Furthermore, improving gait and balance in older diabetic patients could help prevent or lessen the frequency of falls. ${ }^{72}$ Improving resistance and balance training has also been shown to reduce the risk of falls in this group. ${ }^{73}$ Fall prevention programs designed for the elderly have been shown to improve this group's functional performance. ${ }^{74}$ The range of exercises suggested includes exercising for 3 days a week. ${ }^{75}$

The choice of antidiabetic medications that are less likely to affect bone health, particularly in the elderly that are at risk of osteoporosis, is prudent. The enhanced bone-resorption property of TZD may be reduced by using combination therapy with other antidiabetic therapies. ${ }^{52} \mathrm{In}$ addition, bone loss may be prevented by using the available antiosteoporotic drugs, or by the development of a new class of selective TZDs, which may have sparing or even beneficial effects on the bones. ${ }^{69}$ In addition, risk factors for falls such as advanced age, impaired balance, cardiovascular disease, and neuropathy should be evaluated, so as to implement a program that combines regular exercise, vitamin D supplementation, the withdrawal of psychotropic medications, a visual assessment, an environmental hazard assessment and modification, and the use of hip protectors. ${ }^{72}$

\section{Conclusion}

In summary, hypoglycemia-induced falls are common in elderly diabetic individuals who are at risk of fractures and adverse outcomes, including the loss of independence and death. ${ }^{31}$ Many hypoglycemia events can be prevented by using appropriately dosed insulin, which is adjusted based on daily home blood glucose monitors in subjects on insulin therapy. ${ }^{6}$ Avoiding the use of sulfonylureas in patients aged $>65$ years, in those with renal insufficiency, or in those who are receiving basal insulin preparations, can reduce the risk of hypoglycemia. ${ }^{70,71}$ Due to increased risk of hypoglycemia and its complications in this group of the population, maintenance of tight glycemic control should be discouraged. ${ }^{71}$ Other associated risk factors for falls in the elderly should be looked for and addressed accordingly. Oral antidiabetic agents that are least likely to cause hypoglycemia should be the first choice of therapy in this group. 
Metformin and/or dipeptidyl peptidase inhibitors should be used unless contraindicated.

\section{Acknowledgments}

We gratefully acknowledge the clinical advice offered by Dr Scott McCoombe of Deakin University and Dr Ranjit R Rasalam of James Cook University.

\section{Disclosure}

The authors report no conflicts of interest in this work.

\section{References}

1. Shaw JE, Sicree RA, Zimmet PZ. Global estimates of the prevalence of diabetes for 2010 and 2030. Diabetes Res Clin Pract. 2010;87(1):4-14.

2. Wild S, Roglic G, Green A, Sicree R, King H. Global prevalence of diabetes: estimates for the year 2000 and projections for 2030. Diabetes Care. 2004;27(5):1047-1053.

3. International Diabetes Federation [webpage on the Internet]. IDF Diabetes Atlas. 6th ed. Brussels, Belgium: International Diabetes Federation; 2013. Available from: http://www.idf.org/diabetesatlas. Accessed January 1, 2014.

4. Diabetes-UK. Diabetes in the UK 2012: key statistics on diabetes. Available from: http://www.diabetes.org.uk/About_us/What-we-say/ Statistics/Diabetes-prevalence-2013/. Accessed April 20, 2014.

5. Sinclair AJ, Gadsby R, Penfold S, Croxson SC, Bayer AJ. Prevalence of diabetes in care home residents. Diabetes Care. 2001;24(6): 1066-1068.

6. Dominguez LJ, Paolisso G, Barbagallo M. Glucose control in the older patient: from intensive, to effective and safe. Aging Clin Exp Res. 2010;22(4):274-280.

7. Hope SV, Strain WD. Hypoglycemia in the elderly. Diabetic Hypoglycaemia. 2013;6(1):3-10.

8. Bollerslev J, Harris ST, Leder BZ. Medicines and bone loss. J Clin Endocrinol Metab. 2013;98(4):33A-34A.

9. Pedersen-Bjergaard U, Pramming S, Thorsteinsson B. Recall of severe hypoglycaemia and self-estimated state of awareness in type 1 diabetes. Diabetes Metab Res Rev. 2003;19(3):232-240.

10. Akram K, Pedersen-Bjergaard U, Borch-Johnsen K, Thorsteinsson B. Frequency and risk factors of severe hypoglycemia in insulin-treated type 2 diabetes: a literature survey. J Diabetes Complications. 2006; 20(6):402-408.

11. Thomson FJ, Masson EA, Leeming JT, Boulton AJ. Lack of knowledge of symptoms of hypoglycaemia by elderly diabetic patients. Age Ageing. 1991;20(6):404-406.

12. Mutch WJ, Dingwall-Fordyce I. Is it a hypo? Knowledge of the symptoms of hypoglycaemia in elderly diabetic patients. Diabet Med. 1985;2(1):54-56.

13. Jørgensen HV, Pedersen-Bjergaard U, Rasmussen AK, Borch-Johnsen K. The impact of severe hypoglycemia and impaired awareness of hypoglycemia on relatives of patients with type 1 diabetes. Diabetes Care. 2003;26(4):1106-1109.

14. Matyka K, Evans M, Lomas J, Cranston I, Macdonald I, Amiel SA. Altered hierarchy of protective responses against severe hypoglycemia in normal aging in healthy men. Diabetes Care. 1997;20(2):135-141.

15. Leiter LA, Yale JF, Chiasson JL, Harris S, Kleinstiver P, Sauriol L. Assessment of the impact of fear of hypoglycemic episodes on glycemic and hypoglycemia management. Can J Diabetes. 2005;29(3):186-192.

16. Bramlage P, Gitt AK, Binz C, Krekler M, Deeg E, Tschöpe D. Oral antidiabetic treatment in type-2 diabetes in the elderly: balancing the need for glucose control and the risk of hypoglycemia. Cardiovasc Diabetol. 2012;11:122.
17. McAulay V, Deary IJ, Frier BM. Symptoms of hypoglycaemia in people with diabetes. Diabet Med. 2001;18(9):690-705.

18. Deary IJ, Hepburn DA, MacLeod KM, Frier BM. Partitioning the symptoms of hypoglycaemia using multi-sample confirmatory factor analysis. Diabetologia. 1993;36(8):771-777.

19. Henderson JN, Allen KV, Deary IJ, Frier BM. Hypoglycaemia in insulin-treated Type 2 diabetes: frequency, symptoms and impaired awareness. Diabet Med. 2003;20(12):1016-1021.

20. Jaap AJ, Jones GC, McCrimmon RJ, Deary IJ, Frier BM. Perceived symptoms of hypoglycaemia in elderly type 2 diabetic patients treated with insulin. Diabet Med. 1998;15(5):398-401.

21. Brierley EJ, Broughton DL, James OF, Alberti KG. Reduced awareness of hypoglycaemia in the elderly despite an intact counter-regulatory response. QJM. 1995;88(6):439-445.

22. Bremer JP, Jauch-Chara K, Hallschmid M, Schmid S, Schultes B. Hypoglycemia unawareness in older compared with middleaged patients with type 2 diabetes. Diabetes Care. 2009;32(8): 1513-1517.

23. de Galan BE, Schouwenberg BJ, Tack CJ, Smits P. Pathophysiology and management of recurrent hypoglycaemia and hypoglycaemia unawareness in diabetes. Neth J Med. 2006;64(8):269-279.

24. Grisso JA, Schwarz DF, Wishner AR, Weene B, Holmes JH, Sutton RL. Injuries in an elderly inner-city population. $J$ Am Geriatr Soc. 1990;38(12):1326-1331.

25. Palvanen M, Kannus P, Pakkari J, et al. The injury mechanisms of osteoporotic upper extremity fractures among older adults: a controlled study of 287 consecutive patients and their 108 controls. Osteoporos Int. 2000;11(10):822-831.

26. Robinovitch SN, Feldman F, Yang Y, et al. Video capture of the circumstances of falls in elderly people residing in long-term care: an observational study. Lancet. 2013;381(9860):47-54.

27. Morley JE. An overview of diabetes mellitus in older persons. Clin Geriatr Med. 1999;15(2):211-224.

28. Schwartz AV, Hillier TA, Sellmeyer DE, et al. Older women with diabetes have a higher risk of falls: a prospective study. Diabetes Care. 2002;25(10):1749-1754.

29. Volpato S, Leveille SG, Blaum C, Fried LP, Guralnik JM. Risk factors for falls in older disabled women with diabetes: the women's health and aging study. J Gerontol A Biol Sci Med Sci. 2005;60(12): 1539-1545.

30. Volpato S, Maraldi C, Fellin R. Type 2 diabetes and risk for functional decline and disability in older persons. Curr Diabetes Rev. 2010;6(3):134-143.

31. Maurer MS, Burcham J, Cheng H. Diabetes mellitus is associated with an increased risk of falls in elderly residents of a long-term care facility. J Gerontol A Biol Sci Med Sci. 2005;60(9):1157-1162.

32. Gregg EW, Mangione CM, Cauley JA, et al; Study of Osteoporotic Fractures Research Group. Diabetes and incidence of functional disability in older women. Diabetes Care. 2002;25(1):61-67.

33. Johnston SS, Conner C, Aagren M, Ruiz K, Bouchard J. Association between hypoglycaemic events and fall-related fractures in Medicare-covered patients with type 2 diabetes. Diabetes Obes Metab. 2012;14(7):634-643.

34. Briscoe VJ, Davis SN. Hypoglycemia in type 1 and type 2 diabetes: physiology, pathophysiology, and management. Clin Diabetes. 2006;24(3):115-121.

35. Chu E, Meinel N. Severe hypoglycemia and complications in elderly people with diabetes, hypoglycemia in hospitalized patients, and hypoglycemia and fall-related fractures. Diabetic Hypoglycemia. 2012;5(2):24-28.

36. Signorovitch JE, Macaulay D, Diener M, et al. Hypoglycaemia and accident risk in people with type 2 diabetes mellitus treated with noninsulin antidiabetes drugs. Diabetes Obes Metab. 2013;15(4):335-341.

37. Workgroup on Hypoglycemia, American Diabetes Association. Defining and reporting hypoglycemia in diabetes: a report from the American Diabetes Association Workgroup on Hypoglycemia. Diabetes Care. 2005;28(5):1245-1249. 
38. Turchin A, Matheny ME, Shubina M, Scanlon JV, Greenwood B, Pendergrass ML. Hypoglycemia and clinical outcomes in patients with diabetes hospitalized in the general ward. Diabetes Care. 2009;32(7):1153-1157.

39. Foster J, Baillie PA, Strain WD. Hypoglycemia precipitating prolonged QT interval and myocardial ischemia in a patient with coronary heart disease and renal failure. Diabetic Hypoglycemia. 2012;4(3):9-11.

40. Kennedy RL, Henry J, Chapman AJ, Nayar R, Grant P, Morris AD. Accidents in patients with insulin-treated diabetes: increased risk of low-impact falls but not motor vehicle crashes - a prospective registerbased study. J Trauma. 2002;52(4):660-666.

41. Wallace C, Reiber GE, LeMaster J, et al. Incidence of falls, risk factors for falls, and fall-related fractures in individuals with diabetes and a prior foot ulcer. Diabetes Care. 2002;25(11):1983-1986.

42. Pijpers E, Ferreira I, de Jongh RT, et al. Older individuals with diabetes have an increased risk of recurrent falls: analysis of potential mediating factors: the Longitudinal Ageing Study Amsterdam. Age Ageing 2012;41(3):358-365.

43. Miller DK, Lui LY, Perry HM 3rd, Kaiser FE, Morley JE. Reported and measured physical functioning in older inner-city diabetic African Americans. J Gerontol A Biol Sci Med Sci. 1999;54(5):M230-M236.

44. Tilling LM, Darawil K, Britton M. Falls as a complication of diabetes mellitus in older people. J Diabetes Complications. 2006;20(3): $158-162$

45. Schwartz AV, Vittinghoff E, Sellmeyer DE, et al; Health, Aging, and Body Composition Study. Diabetes-related complications, glycemic control, and falls in older adults. Diabetes Care. 2008;31(3) 391-396.

46. DeMott TK, Richardson JK, Thies SB, Ashton-Miller JA. Falls and gait characteristics among older persons with peripheral neuropathy. Am J Phys Med Rehabil. 2007;86(2):125-132.

47. Simoneau GG, Ulbrecht JS, Derr JA, Becker MB, Cavanagh PR Postural instability in patients with diabetic sensory neuropathy. Diabetes Care. 1994;17(12):1411-1421.

48. Dukas LC, Schacht E, Mazor Z, Stähelin HB. A new significant and independent risk factor for falls in elderly men and women: a low creatinine clearance of less than $65 \mathrm{~mL} / \mathrm{min}$. Osteoporos Int. 2005; 16(3):332-338.

49. Brown JS, Vittinghoff E, Wyman JF, et al. Urinary incontinence: does it increase risk for falls and fractures? Study of Osteoporotic Fractures Research Group. J Am Geriatr Soc. 2000;48(7):721-725.

50. Kool B, Ameratunga S, Robinson E. Association between prescription medications and falls at home among young and middle-aged adults. Inj Prev. 2012;18(3):200-203.

51. Huang ES, Karter AJ, Danielson KK, Warton EM, Ahmed AT. The association between the number of prescription medications and incident falls in a multi-ethnic population of adult type- 2 diabetes patients: the diabetes and aging study. J Gen Intern Med. 2010;25(2):141-146.

52. Berlie HD, Garwood CL. Diabetes medications related to an increased risk of falls and fall-related morbidity in the elderly. Ann Pharmacother. 2010;44(4):712-717

53. Kahn SE, Zinman B, Lachin JM, et al; Diabetes Outcome Progression Trial (ADOPT) Study Group. Rosiglitazone-associated fractures in type 2 diabetes: an Analysis from A Diabetes Outcome Progression Trial (ADOPT). Diabetes Care. 2008;31(5):845-851.

54. Meier C, Kraenzlin ME, Bodmer M, Jick SS, Jick H, Meier CR. Use of thiazolidinediones and fracture risk. Arch Intern Med. 2008;168(8) 820-825.

55. Lecka-Czernik B. Bone as a target of type 2 diabetes treatment. Curr Opin Investig Drugs. 2009;10(10):1085-1090.
56. Ivers RQ, Cumming RG, Mitchell P, Attebo K. Visual impairment and falls in older adults: the Blue Mountains Eye Study. J Am Geriatr Soc. 1998;46(1):58-64.

57. Kamel HK, Guro-Razuman S, Shareeff M. The activities of daily vision scale: a useful tool to assess fall risk in older adults with vision impairment. J Am Geriatr Soc. 2000;48(11):1474-1477.

58. Hanlon JT, Landerman LR, Fillenbaum GG, Studenski S. Falls in African American and white community-dwelling elderly residents. J Gerontol A Biol Sci Med Sci. 2002;57(7):M473-M478.

59. Lord SR, Caplan GA, Colagiuri R, Colagiuri S, Ward JA. Sensori-motor function in older persons with diabetes. Diabet Med. 1993;10(7):614-618.

60. Andersen H. Muscular endurance in long-term IDDM patients. Diabetes Care. 1998;21(4):604-609.

61. Jacob G, Costa F, Biaggioni I. Spectrum of autonomic cardiovascular neuropathy in diabetes. Diabetes Care. 2003;26(7):2174-2180.

62. Yoshinari M, Wakisaka M, Nakamura U, Yoshioka M, Uchizono Y, Iwase M. Orthostatic hypertension in patients with type 2 diabetes. Diabetes Care. 2001;24(10):1783-1786.

63. Maurer MS, Cohen S, Cheng H. The degree and timing of orthostatic blood pressure changes in relation to falls in nursing home residents. J Am Med Dir Assoc. 2004;5(4):233-238.

64. Hofbauer LC, Brueck CC, Singh SK, Dobnig H. Osteoporosis in patients with diabetes mellitus. J Bone Miner Res. 2007;22(9):1317-1328.

65. Kurra S, Siris E. Diabetes and bone health: the relationship between diabetes and osteoporosis-associated fractures. Diabetes Metab Res Rev. 2011;27(5):430-435.

66. Cattabiani C, Basaria S, Ceda GP, et al. Relationship between testosterone deficiency and cardiovascular risk and mortality in adult men. J Endocrinol Invest. 2012;35(1):104-120.

67. Kos E, Liszek MJ, Emanuele MA, Durazo-Arvizu R, Camacho P. Effect of metformin therapy on vitamin $\mathrm{D}$ and vitamin $\mathrm{B}_{12}$ levels in patients with type 2 diabetes mellitus. Endocr Pract. 2012;18(2):179-184.

68. Colhoun HM, Livingstone SJ, Looker HC, et al; Scottish Diabetes Research Network Epidemiology Group. Hospitalised hip fracture risk with rosiglitazone and pioglitazone use compared with other glucoselowering drugs. Diabetologia. 2012;55(11):2929-2937.

69. Bilezikian JP, Josse RG, Eastell R, et al. Rosiglitazone decreases bone mineral density and increases bone turnover in postmenopausal women with type 2 diabetes mellitus. $J$ Clin Endocrinol Metab. 2013;98(4):1519-1528.

70. McLaren LA, Quinn TJ, McKay GA. Diabetes control in older people. BMJ. 2013;346:f2625.

71. Inzucchi SE, Bergenstal RM, Buse JB, et al. Management of hyperglycaemia in type 2 diabetes: a patient-centered approach. Position statement of the American Diabetes Association (ADA) and the European Association for the Study of Diabetes (EASD). Diabetologia. 2012;55(6):1577-1596.

72. Allet L, Armand S, de Bie RA, et al. The gait and balance of patients with diabetes can be improved: a randomised controlled trial. Diabetologia. 2010;53(3):458-466.

73. Morrison S, Colberg SR, Mariano M, Parson HK, Vinik AI. Balance training reduces falls risk in older individuals with type 2 diabetes. Diabetes Care. 2010;33(4):748-750.

74. Lee HC, Chang KC, Tsauo JY, Hung JW, Huang YC, Lin SI; Fall Prevention Initiatives in Taiwan (FPIT) Investigators. Effects of a multifactorial fall prevention program on fall incidence and physical function in community-dwelling older adults with risk of falls. Arch Phys Med Rehabil. 2013;94(4):606-615, 615. e1.

75. Zheng J, Pan Y, Hua Y, et al. Strategic targeted exercise for preventing falls in elderly people. J Int Med Res. 2013;41(2):418-426. 


\section{Publish your work in this journal}

Clinical Epidemiology is an international, peer-reviewed, open access journal focusing on disease and drug epidemiology, identification of risk factors and screening procedures to develop optimal preventative initiatives and programs. Specific topics include: diagnosis, prognosis, treatment, screening, prevention, risk factor modification, systematic

Submit your manuscript here: http://www.dovepress.com/clinical-epidemiology-journal reviews, risk \& safety of medical interventions, epidemiology \& biostatical methods, evaluation of guidelines, translational medicine, health policies \& economic evaluations. The manuscript management system is completely online and includes a very quick and fair peer-review system, which is all easy to use. 